\title{
O atendimento privado subsidiado na educação infantil: os convênios e contratos administrativos em análise
}

\author{
The private subsidized care in early childhood education: the covenants and \\ administrative contracts under review
}

\section{El cuidado particular subvencionado de la educación de la primera infancia: los convenios y contratos administrativos en revisión}

\author{
Caroline de Fátima Nascimento de Jesus Azevedo' \\ Raquel Fontes Borghi" \\ 'Universidade Estadual Paulista (UNESP) - SP, Rio Claro - Brasil Email carolinefni@hotmail.com.br \\ "Universidade Estadual Paulista (UNESP) - SP, Rio Claro - Brasil Email raborghi@gmail.com
}

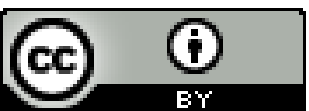

Educação: teoria e prática, Rio Claro, SP, Brasil - eISSN: 1981-8106

Está licenciada sob Licença Creative Common

\begin{abstract}
Resumo
Este trabalho resulta de dissertação de mestrado que teve por objetivo analisar os instrumentos jurídicos adotados em parcerias entre instituições privadas com fins lucrativos e cinco municípios do interior paulista (Araras, Hortolândia, Limeira, Piracicaba e Sumaré) para a oferta de vagas na educação infantil. Objetiva-se verificar se tais instrumentos jurídicos atendem às exigências legais, bem como se configuram parte de estratégias legislativas para alocação de recursos públicos na esfera privada. Trata-se de uma pesquisa qualitativa, de natureza documental. Os procedimentos metodológicos empregados foram a análise documental, a pesquisa bibliográfica e a análise de conteúdo. Por meio da análise de conteúdo constatou-se que os programas municipais não correspondem a uma política transitória para a oferta de vagas na educação infantil, pois fixam prazos longos de vigência das parcerias e preveem a possibilidade de prorrogá-las. Também se observou que a transferência de responsabilidades quanto à execução do atendimento às entidades privadas de finalidade lucrativa, a utilização de termos vagos ou imprecisos e a falta de mecanismos de fiscalização do atendimento pelas prefeituras constituem uma estratégia política de privatização da educação infantil.
\end{abstract}

Palavras-chave: Educação infantil. Instrumentos jurídicos. Privatização. 


\begin{abstract}
This work results from dissertation that aimed to analyze the legal instruments adopted in partnerships between private for-profit institutions and five municipalities in the interior (Araras, Hortolândia, Limeira, Piracicaba and Sumaré) for the supply of places in early childhood education. The objective is to verify that such legal instruments meet the legal requirements as well as to configure part of legislative strategies for allocation of public resources in the private sphere. This is a qualitative research of nature documentary. The methodological procedures used were document analysis, bibliographic research and content analysis. Through content analysis it was found that the municipal programs do not correspond to a transitional policy for the supply of places in early childhood education, as set long periods of validity of partnerships and provide for the possibility to extend them. We also observed that the transfer of responsibilities for the implementation of assistance to private entities for profit purpose, the use of vague or imprecise terms and the lack of care by municipalities surveillance mechanisms constitute a privatization policy strategy of early childhood education.
\end{abstract}

Keywords: Child rearing. Legal instruments. Privatization.

\title{
Resumen
}

En este trabajo los resultados de la tesis que tuvo como objetivo analizar los instrumentos jurídicos adoptados en las asociaciones entre instituciones privadas con fines de lucro y los cinco municipios del interior (Araras, Hortolândia, Limeira, Piracicaba y Sumaré) para la oferta de plazas en la educación infantil. El objetivo es verificar que dichos instrumentos jurídicos cumplen con los requisitos legales, así como para configurar parte de las estrategias legislativas para la asignación de los recursos públicos en la esfera privada. Se trata de una investigación cualitativa de carácter documental. Los procedimientos metodológicos utilizados fueron el análisis de documentos, investigación bibliográfica y análisis de contenido. Por medio de análisis de contenido se encontró que los programas municipales no se corresponden con una política de transición para la oferta de plazas en la educación infantil, según la definición de largos períodos de validez de las asociaciones y prevén la posibilidad de extenderlas. También se observó que la transferencia de responsabilidades para la ejecución de la ayuda a las entidades privadas con fines de lucro, el uso de términos vagos o imprecisos y la falta de atención por municipios mecanismos de vigilancia constituye una estrategia política de privatización de la educación infantil.

Palabras clave: El niño de crianza. Instrumentos jurídicos. Privatización.

\section{Introdução}

Este artigo resulta de dissertação de mestrado que teve por objetivo analisar os instrumentos jurídicos utilizados por parcerias firmadas entre as prefeituras de cinco municípios paulistas (Araras, Hortolândia, Limeira, Piracicaba e Sumaré) e entidades educacionais de finalidade lucrativa para a oferta de educação infantil, com o objetivo de discutir um possível processo de privatização da primeira etapa da educação básica. Esses Educação: Teoria e Prática/ Rio Claro/ Vol. 25, n.50/ p. 466-482/ Set.-Dez. 2015. 
cinco municípios foram identificados em pesquisa coordenada por Borghi (2012), como aqueles que implantaram programas de subsídio público às instituições privadas lucrativas para a oferta da educação infantil. O estudo coordenado por Borghi analisou os arranjos firmados entre prefeituras paulistas e instituições privadas de educação infantil.

Em razão da grande demanda por vagas em creches e da falta de planejamento dos administradores públicos para a criação de espaços para o atendimento educacional, muitos municípios têm custeado a educação infantil por meio do repasse de recursos públicos a entidades privadas com e sem fins lucrativos, conforme apontam diversos estudos (ADRIÃO, 2009; BORGHI, 2012; DOMICIANO, 2009; OLIVEIRA, 2010). Vale dizer que, como alternativa à criação de espaços públicos para o atendimento da educação infantil, os municípios têm repassado recursos públicos a escolas privadas para que estas prestem o serviço diretamente às crianças.

Borghi (2012) aponta que esse repasse de recursos da esfera pública à esfera privada tem sido formalizado por meio de diferentes instrumentos jurídicos.

A presente pesquisa identificou e analisou os instrumentos jurídicos utilizados nos cinco municípios acima citados, por meio do método da análise de conteúdo - conforme proposto por Bardin (2011) - objetivando aferir se tais documentos atendem às exigências legais e, sobretudo, como se dá a relação entre o público e o privado no que diz respeito às políticas educacionais voltadas à educação infantil.

\section{2- Os Instrumentos Jurídicos em Análise}

A literatura nacional é bastante escassa em relação às técnicas de processamento e análise de documentos. Praticamente toda a produção bibliográfica referente à metodologia de pesquisa de análise de conteúdo reporta-se à obra de Laurence Bardin intitulada Análise de conteúdo.

Essa obra foi desenvolvida nos Estados Unidos, no início do século XX, e vem sendo amplamente divulgada como uma poderosa ferramenta de análises pormenorizadas dos conteúdos de documentos. Seu trabalho, além de ser a principal obra na atualidade sobre a metodologia de análise de conteúdo, também é acessível do ponto de vista didático, pois 
trabalha conceitos e casos práticos que auxiliam o pesquisador na busca por resultados em sua esfera de pesquisa.

Bardin (2011, p. 37) explica que :

[...] não se trata de um instrumento, mas de um leque de apetrechos; ou, com maior rigor, será um único instrumento, mas marcado por uma grande disparidade de formas e adaptável a um campo de aplicação muito vasto: as comunicações.

A utilização da metodologia da análise de conteúdo nas pesquisas qualitativas vem ganhando espaço. Para Godoy (1995, p. 23), qualquer comunicação “que veicule um conjunto de significações de um emissor para um receptor pode, em princípio, ser decifrada pela técnica de análise de conteúdo", a qual, tendo em vista que a abordagem qualitativa não se apresenta como uma proposta rigidamente estruturada, "permite que a imaginação e a criatividade levem os investigadores a propor trabalhos que explorem novos enfoques".

Trata-se de um método de pesquisa que "trabalha com a palavra, permitindo de forma prática e objetiva produzir inferências do conteúdo da comunicação de um texto replicáveis ao seu contexto social" (CAREGNATO; MUTTI, 2006, p. 682).

A fim de responder a algumas questões importantes, sobretudo as relacionadas aos aspectos de política educacional, realizou-se a análise de conteúdo de cada um dos instrumentos jurídicos, valendo-nos, para tanto, dos critérios metodológicos e etapas idealizados por Bardin (2011): 1) a pré-análise; 2) a exploração do material; e 3) o tratamento dos resultados, a inferência e a interpretação.

Em uma primeira etapa foram coletados os instrumentos jurídicos e formuladas algumas hipóteses e objetivos. As seguintes questões foram elaboradas:

a) Os instrumentos jurídicos analisados, ao regulamentarem as parcerias com a iniciativa privada de finalidade lucrativa, correspondem a uma forma provisória de oferta de vagas na educação infantil?

b) Os instrumentos jurídicos analisados correspondem a uma estratégia política de privatização da educação infantil por meio de parcerias entre prefeituras e entidades privadas de finalidade lucrativa?

c) Há diferenças significativas entre os formatos dos programas municipais analisados cujos instrumentos jurídicos têm natureza diversa (convênios e concessões)? 
Em seguida, após a detalhada leitura dos documentos, optou-se por categorizar os indicadores de acordo com as seguintes cláusulas inseridas nos referidos documentos, isso porque foi identificada certa repetição dessas categorias nos instrumentos analisados:
a) Ano de elaboração da lei municipal
b) Natureza Jurídica do instrumento jurídico
c) Objeto
d) Critérios de acesso
e) Responsabilidades da Prefeitura
f) Responsabilidades da escola
g) Prazo de vigência
h) Valor do repasse
i) Forma de subsídio
j) Prestação de contas

A partir dos indicadores definidos foram construídos quadros, possibilitando uma melhor visualização dos indicadores referentes aos cinco instrumentos jurídicos em estudo. $\mathrm{O}$ Quadro 1 traz alguns desses indicadores.

Quadro 1 - Ano da legislação municipal, partido político, natureza jurídica e objeto dos instrumentos jurídicos

\begin{tabular}{|c|c|c|c|c|c|}
\hline & Piracicaba & Hortolândia & Sumaré & Limeira & Araras \\
\hline Ano & 2001 & 2005 & 2007 & 2003 & 2009 \\
\hline $\begin{array}{l}\text { Partido } \\
\text { político }\end{array}$ & PT & PT & PT & PSDB & PT \\
\hline $\begin{array}{l}\text { Natureza } \\
\text { jurídica }\end{array}$ & $\begin{array}{ll}\text { Termo } & \mathrm{de} \\
\text { convênio } & \end{array}$ & $\begin{array}{ll}\text { Termo } & \mathrm{de} \\
\text { convênio } & \end{array}$ & $\begin{array}{ll}\text { Termo } & \mathrm{de} \\
\text { convênio } & \end{array}$ & $\begin{array}{ll}\text { Termo } & \mathrm{de} \\
\text { concessão } & \end{array}$ & $\begin{array}{l}\text { Termo } \\
\text { concessão }\end{array}$ \\
\hline Objeto & $\begin{array}{ll}\text { Minimizar } & \text { a } \\
\text { falta de vagas } & \text { e } \\
\text { atender } & \text { à } \\
\text { demanda } & \end{array}$ & $\begin{array}{ll}\text { Minimizar } & \text { a } \\
\text { falta de vagas } & \text { e } \\
\text { atender } & \text { à } \\
\text { demanda } & \end{array}$ & $\begin{array}{ll}\text { Minimizar } & \text { a } \\
\text { falta de vagas } & \text { à } \\
\text { atender } & \text { à } \\
\text { demanda } & \end{array}$ & $\begin{array}{l}\text { Concessão de } \\
\text { bolsas }\end{array}$ & $\begin{array}{l}\text { Concessão } \\
\text { bolsas }\end{array}$ \\
\hline $\begin{array}{l}\text { Prazo } \\
\text { vigência }\end{array}$ & $\begin{array}{l}\text { Coincidente } \\
\text { com o exercício } \\
\text { financeiro }\end{array}$ & $\begin{array}{l}\text { Fixou prazo } \\
\text { certo }\end{array}$ & $\begin{array}{l}\text { Coincidente } \\
\text { com o exercício } \\
\text { financeiro }\end{array}$ & $\begin{array}{l}\text { Coincidente } \\
\text { com o exercício } \\
\text { financeiro }\end{array}$ & $\begin{array}{l}\text { Coincidente com } \\
\text { o exercício } \\
\text { financeiro }\end{array}$ \\
\hline
\end{tabular}

Fonte: as autoras, com base na análise dos instrumentos jurídicos dos municípios de Araras, Hortolândia, Limeira, Piracicaba e Sumaré.

A leitura dos instrumentos jurídicos estudados possibilitou perceber que há uma relação de similaridade entre eles. Foi possível categorizá-los em dois grandes blocos: de um lado, os termos de convênio dos municípios de Piracicaba, Hortolândia e Sumaré; de outro, os termos de concessão dos municípios de Limeira e Araras. 
Embora os termos de convênio e os termos de concessão sejam, aparentemente, diferentes em virtude do nomen juris a eles atribuído, fato é que em vários aspectos são muito parecidos ${ }^{1}$.

A título de exemplo, ambos dispõem sobre a necessidade de inscrição da entidade parceira junto aos órgãos municipais (Conselho Municipal de Defesa dos Direitos da Criança e do Adolescente e Secretaria de Educação), estabelecem que é dever das escolas encaminhar um controle de frequência mensal à Prefeitura e obrigam-nas a cuidar da guarda dos alunos, bem como a oferecer alimentação adequada. Também estabelecem prazo de vigência coincidente, permitindo, ainda, a renovação ou a prorrogação do ajuste.

Essa grande semelhança entre os documentos nos leva a supor, inclusive, que, talvez por pura falta de técnica jurídica dos administradores públicos de Araras e Limeira, os respectivos instrumentos jurídicos receberam o nomen juris de concessão, não por se referirem ao instituto jurídico da concessão administrativa, mas porque objetivavam conceder vagas na forma de bolsas de estudo às crianças pertencentes à educação infantil.

Tal similitude pode ser explicada pela proximidade geográfica dos municípios no Estado de São Paulo e, também, pelo alinhamento político dos governos municipais especialmente os do Partido dos Trabalhadores (PT) - à época da criação de sua política de concessão de bolsas a entidades privadas de finalidade lucrativa.

Com exceção do município de Limeira, cuja lei municipal que instituiu o programa para a concessão de bolsas foi implementada durante o governo do PSDB, nos demais municípios todas as leis municipais foram aprovadas durante o governo do PT.

Gouveia (2009, p. 46) nos ajuda a compreender as possíveis justificativas da adoção dessa política de formação de parcerias com a esfera privada por parte do PT:

Subvencionar entidades comunitárias tem sido uma estratégia de ampliação de vagas utilizada por governos de todos os matizes partidários no Brasil. Ainda que à esquerda do espectro político tal prática seja adotada, compreende-se aqui que essa estratégia corresponde a uma tese de direita, pois, em geral, está associada à falta de recursos para o provimento direto das vagas em estabelecimentos públicos. Na literatura recente ou nas

\footnotetext{
${ }^{1}$ Há diferenças jurídicas relevantes entre convênios e concessão administrativa. Enquanto no convênio os interesses envolvidos são recíprocos (todos os participantes querem a mesma coisa), na concessão administrativa os interesses são opostos e contraditórios. Quanto ao repasse de recursos, o conveniado fica vinculado à utilização prevista no ajuste, enquanto que, no contrato, o valor pago integra o patrimônio da entidade que o recebeu.

Educação: Teoria e Prática/ Rio Claro/ Vol. 25, n.50/ p. 466-482/ Set.-Dez. 2015.
} 
experiências divulgadas, não foram encontrados argumentos quanto à pertinência da realização de convênios por razões pedagógicas ou de estratégia de autogestão comunitária, argumentos esses que poderiam aproximar-se de teses desestatizantes à esquerda.

Em relação ao objeto do convênio/concessão fica clara a resposta a uma demanda, ainda grande, por atendimento em creches e pré-escolas. Estudo coordenado por Borghi (2012) já apontava a demanda como principal justificativa dos municípios para a celebração de convênios com instituições privadas, particularmente daqueles de maior porte populacional.

Ressalta-se, ainda, que a palavra vaga tem presença e frequência marcantes nos instrumentos jurídicos analisados, o que pode indicar uma preocupação política, decorrente tanto de uma pressão popular por oferta de vagas, quanto de uma atuação mais específica do Ministério Público. Além de ser financeiramente mais viável para as prefeituras, tal estratégia apresenta-se como uma solução mais rápida.

A atuação do Ministério Público, que busca garantir vagas a todas as crianças do município que delas necessitarem, torna-se controversa se não houver uma discussão sobre o crescimento desse atendimento na própria rede municipal.

Com efeito, esses pleitos por vagas na educação infantil também induzem a formação de parcerias dos municípios com entidades privadas com ou sem finalidade lucrativa. $\mathrm{O}$ município, com vistas a assegurar o acesso da criança de até três anos à creche, acaba tomando medidas que, a princípio, parecem transitórias, mas que vão se perpetuando com o passar do tempo.

Por fim, quanto ao prazo de vigência, com exceção do instrumento jurídico do município de Hortolândia, todos os demais documentos fixaram como prazo de vigência o período correspondente ao do exercício financeiro. Sem exceção, todos previram a possibilidade de prorrogação das parcerias.

Essa observação permite apontar que não há uma ideia de provisoriedade na formação das parcerias entre municípios e entidades privadas de finalidade lucrativa. Ao contrário, os documentos analisados demonstram que há um interesse político pela permanência dessa estratégia de repasse de recursos públicos à esfera privada, com a consequente transferência de execução do serviço. Para reforçar essa linha argumentativa, basta observar o ano de 
criação das leis municipais que autorizaram a elaboração dos termos ora analisados ${ }^{2}$ e atentar para o fato de que tais parcerias são realidade nesses municípios até os dias atuais.

Além do fato da permanência de tais programas, estudos evidenciam o crescimento dos mesmos. Costa (2014), constatou que, no período compreendido entre 2009 e 2013, houve uma ampliação de $166 \%$ no número de concessões de bolsas em escolas particulares vinculadas ao Programa Pró-Creche no município de Araras. A rede municipal de atendimento à criança menor de três anos cresceu menos que a rede privada. No que se refere ao número de matrículas ligadas ao Programa Pró-Creche, houve um crescimento de $90 \%$ entre 2009 e 2013, enquanto a rede municipal de creche cresceu apenas 23\% no mesmo período (COSTA, 2014, p. 91).

Outro dado importante é a forma de reajuste dos valores repassados às instituições privadas de finalidade lucrativa pelo Poder Público: eles são definidos, ano a ano, mediante decreto expedido pelo Poder Executivo. Trata-se de outra demonstração de que não há um caráter de transitoriedade nessa política municipal, uma vez que o Poder Executivo poderá adaptar o negócio de acordo com sua conveniência sem nenhuma dificuldade.

É possível afirmar, portanto, que está havendo um processo de perpetuação dessas práticas de formação de parcerias com a esfera privada de finalidade lucrativa, num caminho contrário à presença do Estado nas políticas públicas educacionais e às diretrizes constitucionais permitidas.

O Quadro 2 apresenta a divisão de responsabilidades entre a Prefeitura e a instituição privada parceira.

Quadro 2 - Divisão de responsabilidades

\begin{tabular}{|l|l|l|l|l|l|}
\hline & Piracicaba & Hortolândia & Sumaré & Limeira & Araras \\
\hline $\begin{array}{l}\text { Responsabilidades } \\
\text { da Prefeitura }\end{array}$ & Três itens & Quatro itens & Três itens & Dois itens & Dois itens \\
\hline $\begin{array}{l}\text { Responsabilidades } \\
\text { da instituição } \\
\text { privada }\end{array}$ & Sete itens & Dez itens & Doze itens & $\begin{array}{l}\text { Quatorze } \\
\text { itens }\end{array}$ & Treze itens \\
\hline
\end{tabular}

Fonte: as autoras, com base na análise dos instrumentos jurídicos dos municípios de Araras, Hortolândia, Limeira, Piracicaba e Sumaré.

\footnotetext{
2 Piracicaba (2001), Hortolândia (2005), Sumaré (2007), Limeira (2003) e Araras (2009).

Educação: Teoria e Prática/ Rio Claro/ Vol. 25, n.50/ p. 466-482/ Set.-Dez. 2015.
} 
O quadro evidencia que a repartição de responsabilidades entre as prefeituras e as entidades de finalidade lucrativa não ocorre de forma harmoniosa. Ao contrário, resta evidente que há uma transferência de responsabilidades do setor público para o privado, que fica comprometido a assumir toda a execução do atendimento.

Através da quantidade de itens sob responsabilidade das prefeituras, considerando especialmente os termos de concessão dos municípios de Araras e Limeira, vê-se que eles conferem às prefeituras apenas o dever de colaborar e apoiar a execução do ajuste, bem como o de efetuar o pagamento das vagas postas à disposição como objetos do ajuste.

No que tange aos termos de convênio celebrados nos municípios de Piracicaba, Hortolândia e Sumaré, constata-se um crescimento das responsabilidades atribuídas às escolas privadas de finalidade lucrativa, o que revela um contínuo processo de transferência de responsabilidades ao setor privado, concretizando, dessa forma, a ideia de privatização da educação infantil.

Além disso, os termos de convênio estudados são, praticamente, cópias uns dos outros (o que, de fato, demonstra o alinhamento político dos respectivos governos municipais), e com o passar do tempo houve uma tentativa de incremento dos instrumentos jurídicos no que se refere às responsabilidades atribuídas ao setor privado. Há sete itens no termo de convênio do município de Piracicaba, de 2001, e doze itens no termo de convênio do município de Sumaré, de 2007.

Nos instrumentos jurídicos dos municípios de Limeira e Araras, que utilizam o termo de concessão, a transferência de responsabilidades é ainda maior. Restam às prefeituras apenas as responsabilidades de colaborar e apoiar a realização dos fins a que se destina o instrumento jurídico firmado, além da obrigação de pagar as vagas. Às escolas cabe toda a responsabilidade de execução do atendimento, sem que, contudo, os mecanismos de controle da atividade pelo setor público tenham sido disciplinados.

Nesses casos, o que significa colaborar e apoiar? Como poderiam as prefeituras cumprir tais responsabilidades se não há cláusula expressa delimitando essa determinação? Tais instrumentos jurídicos, denominados termos de concessão, simplesmente nada dizem a respeito, o que ratifica a afirmação de que a educação infantil está passando por um processo de privatização. 
Essa clara transferência de responsabilidades do setor público para o privado segue, exatamente, a mesma direção daquilo que se propunha na Reforma do Aparelho do Estado, em 1995. Sob o argumento de que o Estado é ineficiente e burocrático para dar conta de todas as responsabilidades a ele atribuídas, o melhor caminho seria transferir o planejamento e a prestação do atendimento à esfera privada.

Entretanto, tem-se observado que as parcerias ora estudadas vêm sendo firmadas com instituições privadas porque os municípios acabam gastando menos do que gastariam para investir em sua própria rede de atendimento. Por consequência, como apontado por diversos estudos (BEZERRA, 2008; OLIVEIRA, 2010; BORGHI, 2012), as parcerias firmadas entre Poder Público e instituições privadas têm provocado a baixa qualidade do atendimento, o que vai de encontro à proclamada eficiência do setor privado que fundamenta a defesa da privatização.

Em virtude do aumento das responsabilidades transferidas à esfera privada e do controle estatal praticamente nulo, as escolas privadas reduzem os seus custos com alimentação, corpo docente e infraestrutura para que o empreendimento seja financeiramente atraente, como evidenciam os estudos de Oliveira (2013) e Costa (2014), referentes aos municípios de Limeira e Araras, respectivamente.

A redução de custos interfere negativamente na qualidade do ensino prestado. Uma educação de qualidade implica investimentos diversos, como valorização dos profissionais docentes e auxiliares, infraestrutura adequada e alimentação apropriada, fatores que provocam altos custos para aquele que realiza o atendimento (PINTO, 2007).

Abaixo, o Quadro 3 trata dos subsídios às instituições privadas lucrativas.

Quadro 3 - os subsídios para as instituições privadas - repasse, forma de subsídio e prestação de contas

\begin{tabular}{|l|l|l|l|l|l|}
\hline Município & Piracicaba & Hortolândia & Sumaré & Limeira & Araras \\
\hline Valor do repasse & Nada consta & R $99.850,00$ & Nada consta & Nada consta & Nada consta \\
\hline Forma de subsídio & Per capita & Per capita & Per capita & $\begin{array}{l}\text { Per capita e } \\
\text { aquisição de } \\
\text { material }\end{array}$ & $\begin{array}{l}\text { Per capita e } \\
\text { aquisição de } \\
\text { material }\end{array}$ \\
\hline Prestação de contas & Nada consta & Nada consta & Nada consta & $\begin{array}{l}\text { Por meio de } \\
\text { relatórios e } \\
\text { ofícios }\end{array}$ & $\begin{array}{l}\text { Por meio de } \\
\text { relatórios e } \\
\text { ofícios }\end{array}$ \\
\hline
\end{tabular}

Fonte: As autoras, com base na análise dos instrumentos jurídicos dos municípios de Araras, Hortolândia, Limeira, Piracicaba e Sumaré. 
Com exceção do instrumento jurídico do município de Sumaré, os documentos dos demais municípios investigados dispõem que as vagas serão distribuídas na forma de bolsas, e, nos casos de Araras e Limeira, além da previsão da compra de vagas, há, também, a destinação de recursos para a compra de material.

Destaque-se que a forma de subsídio é exclusivamente per capita em três dos cinco municípios investigados (Hortolândia, Piracicaba e Sumaré), isto é, o valor total do repasse de recursos públicos às instituições privadas de finalidade lucrativa é calculado segundo o número total de matrículas. Nos municípios de Araras e Limeira, a forma de subsídio abrange a per capita acrescida de recursos para a aquisição e o fornecimento de material escolar.

Embora os documentos não se refiram a qualquer legislação que permita a formação de parceria do Poder Público com setores da esfera privada de finalidade lucrativa para a concessão de bolsas de estudo, a suposição é de que as prefeituras interpretaram tanto a Constituição Federal, quanto os artigos 70, VI, e 77, § $1^{\circ}$, da Lei de Diretrizes e Bases da Educação (Lei no 9.394/96), de forma equivocada como um permissivo legal para a criação dos programas municipais ora estudados. Há que se registrar que não é permitida a concessão de bolsas de estudos para o atendimento de alunos da educação infantil em ambientes privados que objetivam o lucro.

A Constituição Federal determina que os recursos públicos podem ser destinados às escolas comunitárias, confessionais ou filantrópicas, desde que elas comprovem finalidade não lucrativa e apliquem seus excedentes financeiros em educação (artigo 213, inciso I). E o § $1^{\underline{0}}$ do mesmo artigo 213 da Constituição Federal permite a destinação de recursos públicos na forma de bolsas de estudo apenas para os ensinos fundamental e médio (BRASIL, 1988).

Ainda, como dito, o inciso VI do artigo 70 da Lei de Diretrizes e Bases da Educação (Lei n ${ }^{\circ}$ 9.394/96) autoriza a concessão de bolsas de estudo a alunos de escolas privadas. Mas, numa interpretação sistemática desse dispositivo com outros da própria LDB, essas escolas privadas são as comunitárias, confessionais ou filantrópicas que preencham os requisitos dos incisos I, II, III e IV do artigo 77: comprovação de finalidade não lucrativa; aplicação de seus excedentes em educação; garantia da destinação de seu patrimônio a outra instituição sem fim lucrativo ou ao Poder Público, em caso de encerramento de suas atividades; e prestação de contas dos recursos recebidos ao Poder Público. 
É o caput do próprio artigo 77 da LDB que define as escolas privadas em questão como comunitárias, confessionais ou filantrópicas, e o $\S 1^{\underline{0}}$ do mesmo artigo apenas enfatiza que, no caso de haver concessão de bolsas de estudo, o procedimento deverá observar os termos da lei, isto é, deverão ser satisfeitos os requisitos do artigo 70 da LDB.

Ressalta-se, ainda, a impossibilidade de destinação dos recursos do Fundeb (Lei $\mathrm{n}^{\underline{0}}$ 11.494/07) a tais parcerias, pois o artigo $8^{\underline{o}}$, especialmente em seus $\S \S 1^{\underline{o}}, 2^{\underline{o}}$ e $6^{\underline{o}}$, também impede a distribuição de recursos às entidades que deixarem de comprovar finalidade não lucrativa (BRASIL, 2007).

Em relação à prestação de contas referente à execução dos termos de convênio, não há unidades de registro, o que pode refletir uma estratégia proposital de dar liberdade às entidades privadas quanto ao uso do dinheiro público.

Embora exijam a apresentação da lista de frequência dos alunos atendidos, os instrumentos jurídicos não fixam a quantidade de alunos beneficiários, tampouco o valor atribuído a cada vaga e ao benefício, se houver.

Tal procedimento é contrário à prática de formação de convênios. A lei $n^{0} 8.666$, de 1993, no $\S 5^{\circ}$ do artigo 116 , determina que as receitas financeiras auferidas serão, obrigatoriamente, computadas a crédito do convênio e aplicadas exclusivamente no objeto de sua finalidade, devendo constar de demonstrativo específico que integrará as prestações de contas do ajuste (BRASIL, 1993)

Uma pesquisa realizada no site do Tribunal de Contas do Estado de São Paulo sobre as contas anuais dos cinco municípios pesquisados demonstrou que não há grandes discussões acerca do repasse de recursos públicos às instituições privadas. O município de Piracicaba, por exemplo, é o que apresentou maior quantidade de questionamentos junto ao Tribunal de Contas do Estado (TCESP) ${ }^{3}$ desde a edição da lei municipal que instituiu o Programa BolsaCreche.

As contas apresentadas em 2008 e 2009, pelo município de Piracicaba, foram desaprovadas no que se refere ao ensino por causa da constatação de irregularidades: ora porque as entidades conveniadas pelo Programa Bolsa-Creche não preencheram todas as

\footnotetext{
${ }^{3}$ As contas anuais dos municípios de Araras e Sumaré, desde 2009 e 2007 respectivamente, não fazem qualquer menção às parcerias firmadas com instituições privadas para a oferta de vagas na educação infantil. Pesquisa realizada no site do Tribunal de Contas do Estado de São Paulo (www.tce.sp.gob.br).

Educação: Teoria e Prática/ Rio Claro/ Vol. 25, n.50/ p. 466-482/ Set.-Dez. 2015.
} 
vagas disponíveis, embora tenham recebido recursos integrais ${ }^{4}$, ora porque detectado um pagamento da ordem de 213.964,89 reais a empresas privadas por vagas sem o efetivo uso.

Em Hortolândia, consta apenas um registro nas contas referentes ao exercício de 2009. Nele, o chefe do Poder Executivo Municipal foi notificado para justificar o gasto de mais de 2 milhões de reais em convênios entre a Administração e instituições de ensino infantil. Expostas as justificativas pela Administração Municipal, o conselheiro do TCE-SP deu-se por satisfeito, com o argumento de que tal gasto representa apenas $8,8 \%$ do total registrado para a categoria na qual foram incluídos os repasses ${ }^{5}$.

Nos instrumentos jurídicos dos municípios de Limeira e Araras (ambos termos de concessão), há previsão de prestação de contas. As concessionárias devem entregar ao Poder Público documentos que comprovem a utilização da verba, expedindo relatórios e ofícios.

Note-se que, no caso das concessões administrativas, não há determinação legislativa para que a empresa concessionária preste contas dos recursos públicos a ela direcionados. Uma vez repassado o valor total para a execução do serviço ou da obra, cabe à concessionária decidir como serão empregados tais recursos.

Por fim, quanto à fiscalização dos recursos também não há, em nenhum dos documentos analisados, cláusulas que tratem da forma de fiscalização dos municípios em relação ao atendimento prestado.

Nos termos de convênio, entre as incumbências das prefeituras está o dever de fiscalizar, mas os documentos não mencionam a forma pela qual isso será feito, tampouco estabelecem punições no caso de descumprimento, por parte das entidades parceiras, de quaisquer das responsabilidades a elas atribuídas.

Ainda que o termo de convênio não estabeleça as condições para que haja a efetiva fiscalização do cumprimento dos objetivos da parceria, cabe ao município esse mister, já

\footnotetext{
${ }^{4}$ TC-001670/026/08. Segunda Câmara do Tribunal de Contas do Estado de São Paulo. Sessão de 06/07/2011. Pedido de Reexame. Conselheiro: Renato Martins Costa. Disponível em: <http://www2.tce.sp.gov.br/arqs_juri/pdf/136574.pdf>. Acesso em: 03 mar. 2014.

${ }^{5}$ TC-000608/026/09. Primeira Câmara do Tribunal de Contas do Estado de São Paulo. Sessão de 30/08/2011. Parecer. Conselheiro: Eduardo Bittencourt Carvalho. Disponível em: <http://www2.tce.sp.gov.br/arqs_juri/pdf/143714.pdf>. Acesso em: 03 mar. 2014. Educação: Teoria e Prática/ Rio Claro/ Vol. 25, n.50/ p. 466-482/ Set.-Dez. 2015.
} 
que, no caso dos convênios com instituições privadas sem finalidade lucrativa, as responsabilidades são divididas e assumidas de forma colaborativa entre instituição e Poder Público. A ausência de cláusula que estabeleça o dever de fiscalização pelos municípios pode significar uma tentativa de delegação total de responsabilidades às instituições privadas parceiras.

\section{3- Considerações finais}

Concluídas as análises interpretativas específicas acerca do conteúdo dos instrumentos jurídicos estudados, faz-se necessário retornar às três questões principais, formuladas no início deste estudo.

Graças a todo o trajeto metodológico traçado, é possível afirmar, em resposta à primeira questão, que os instrumentos jurídicos analisados não correspondem a uma forma provisória de oferta de vagas na educação infantil. Eles fixam prazos longos para a vigência das parcerias (o exercício financeiro), preveem a possibilidade de prorrogá-las e instituem formas de reajuste por decreto a ser expedido pelo Poder Executivo, constituindo práticas que vêm sendo adotadas há certo tempo, como no caso do município de Piracicaba, que criou o Programa Bolsa-Creche em 2001 e ainda se vale dessa forma de parceria para criar vagas na educação infantil.

No que toca ao segundo questionamento, pode-se afirmar, em vista das análises realizadas, que os instrumentos jurídicos estudados de fato correspondem a uma estratégia política de privatização da educação infantil, um processo que vem se consolidando por meio da formação de parcerias entre prefeituras e entidades privadas inclusive de finalidade lucrativa, como já evidenciaram outros estudos (ADRIÃO, 2009; DOMICIANO, 2009; BORGHI, 2012; OLIVEIRA, 2013; COSTA, 2014).

A transferência de responsabilidades da esfera pública para a privada - tanto por meio de cláusulas que estabelecem tais responsabilidades, quanto por meio da utilização de termos vagos ou imprecisos -, a inexistência de um controle de contas e a ausência de mecanismos de fiscalização do atendimento pelas Prefeituras são fatores que conduzem à Educação: Teoria e Prática/ Rio Claro/ Vol. 25, n.50/ p. 466-482/ Set.-Dez. 2015. 
resposta afirmativa para a segunda grande questão desta investigação e podem indicar que está havendo um processo de precarização do atendimento na educação infantil.

Quanto à terceira indagação, percebe-se que, embora os instrumentos jurídicos tenham sido nomeados ora como convênio, ora como concessão, não há diferenças significativas entre os formatos dos programas municipais criados. Todos os programas pesquisados permitem o oferecimento de educação infantil em ambientes privados que visam ao lucro, apesar de terem recebido nomen juris diverso.

\section{Referências}

ADRIÃO, T. (Coord.). Estratégias municipais para a oferta da educação básica: uma análise de parcerias público-privado no Estado de São Paulo. Relatório de pesquisa: Fapesp, 2009.

AZEVEDO, C. de F. N. de J. Parcerias entre municípios paulistas e entidades privadas com fins lucrativos para a oferta de educação infantil: análise dos instrumentos jurídicos adotados. 2014. 182f. Dissertação (Mestrado em Educação) - Universidade Estadual Paulista, Rio Claro, 2014.

BARDIN, L. Análise de conteúdo. Tradução Luís Antero Reto, Augusto Pinheiro. São Paulo: Edições 70, 2011.

BEZERRA, E. P. Parceria público-privada nos municípios de Brotas e Pirassununga: estratégias para a oferta do ensino? 2008. 181f. Dissertação (Mestrado em Educação) Universidade Estadual Paulista, Rio Claro, 2008.

BORGHI, R. F. Oferta educacional nas creches: arranjos institucionais entre o público e o privado. Relatório de pesquisa: CNPq, 2012.

BRASIL. Constituição da República Federativa do Brasil de 1988. Brasília: Casa Civil, 1988. Disponível em: <http://www.planalto.gov.br/ccivil_03/Constituicao/Constituicao.htm>. Acesso em: 12 set. 2013.

BRASIL. Lei no 8.666, de 21 de junho de 1993. Regulamenta o art. 37, inciso XXI, da Constituição Federal, institui normas para licitações e contratos da Administração Pública e dá outras providências. Brasília: Casa Civil, 1993. Disponível em:

<http://www.planalto.gov.br/ccivil_03/Leis/L9394.htm>. Acesso em: 06 mar. 2013.

BRASIL. Lei no 9.394, de 20 de dezembro de 1996. Estabelece as diretrizes e bases da educação nacional. Brasília: Casa Civil, 1996. Disponível em:

<http://www.planalto.gov.br/ccivil_03/Leis/L8666cons.htm>. Acesso em: 06 mar. 2013. 
BRASIL. Lei no 11.494, de 20 de junho de 2007. Regulamenta o Fundo de Manutenção e Desenvolvimento da Educação Básica e de Valorização dos Profissionais da Educação FUNDEB, de que trata o art. 60 do Ato das Disposições Constitucionais Transitórias; altera a Lei no 10.195, de 14 de fevereiro de 2001; revoga dispositivos das Leis nos 9.424, de 24 de dezembro de 1996, 10.880, de 9 de junho de 2004, e 10.845, de 5 de março de 2004; e dá outras providências. Brasília: Casa Civil, 2007. Disponível em: <http://www.planalto.gov.br/ccivil_03/_Ato2007-2010/2007/Lei/L11494.htm>. Acesso em: 23 abr. 2013.

CAREGNATO, R. C. A.; MUTTI, R. Pesquisa qualitativa: análise de discurso versus análise de conteúdo. Texto Contexto Enferm, Florianópolis, v. 15, n.4, p. 679-684, Out-Dez. 2006. Disponível em: <http://www.scielo.br/pdf/tce/v15n4/v15n4a17>. Acesso em: 01 jun. 2014.

COSTA, B. A. da. Programa Pró-Creche e o atendimento público municipal: um olhar para as condições da oferta de educação para a primeira infância. 2014. 256f. Dissertação (Mestrado em Educação) - Universidade Estadual Paulista, Rio Claro, 2014.

DOMICIANO, C. A. O programa "Bolsa Creche" nos municípios paulistas de Piracicaba e Hortolândia: uma proposta para alocação de recursos estatais à educação privada? 2014. 226f. Dissertação (Mestrado em Educação) - Universidade Estadual Paulista, Rio Claro, 2009.

GODOY, A. S. Pesquisa Qualitativa: tipos fundamentais. Rev.de Administração de Empresas, São Paulo, v. 35, n. 3, p. 20-29, Mai/Jun. 1995.

GOUVEIA, A. B. Direita e esquerda na política educacional: democracia, partidos e disputas entre projetos de administração pública municipal no Brasil. Rev. Bras. de Estudos Pedagógicos, v. 90, n. 224, p. 32-58, Jan./Abr. 2009.

OLIVEIRA, J. dos S. O atendimento público e privado concessionário na educação infantil: um olhar sobre as condições de oferta. 2013. 198f.Dissertação (Mestrado em Educação) - Universidade Estadual Paulista, Rio Claro, 2013.

OLIVEIRA, J. dos S. Oferta educacional nas creches e parcerias público-privado nos municípios paulistas de $\mathbf{1 0 0 . 0 0 0}$ a $\mathbf{5 0 0 . 0 0 0}$ habitantes. 2010. 143f. Trabalho de conclusão (Licenciatura em Pedagogia) - Universidade Estadual Paulista, Rio Claro, 2010.

PINTO, J. M. de R. A política recente de fundos para o financiamento da educação e seus efeitos no pacto federativo. Rev. Educ. \& Sociedade, Campinas, v. 28, n. 100 - Especial, p. 877.897, Out. 2007. 
Recebido em: 28/02/2015

Revisado em: 12/08/2015

Aprovado para publicação em: 24/08/2015

Publicado em: 22/12/2015

Educação: Teoria e Prática/ Rio Claro/ Vol. 25, n.50/ p. 466-482/ Set.-Dez. 2015. 